\title{
An Experimental Study on Behaviors of Beam-Column Joint Wrapped With Aramid Fiber
}

\author{
V. KOWSALYAD. \\ ME-Structural Engineering \\ Jai Shriram Engineering College, \\ Avinashipalayam
}

\author{
Dr. ASHOK KUMAR, M.E., \\ Asst. Professor (Dept of Civil Engg) \\ Jai Shriram Engineering College, \\ Avinashipalayam
}

\begin{abstract}
Concrete is a composite construction material plays a vital role in the construction of the nation's infrastructure. The failure of the structure are mainly due to the failure of the concrete in beam, column joints.In recent days more technical researches are going on to avoid the beam-column joints failure. In this experiment we add the aramid fiber to check the behavior of beamcolumn joints and externally wrapped with aramid fiber was test to failure. Using an arrangement which transfer horizontal moment to the joints of the beam-column through two opposite cantilever moment arms.Aramid fiber is a class of synthetic fibers and heat resistant. They are fibers in which the strength of the chemical bond can be exploited due to the reason the chain molecules are highly oriented along the fiber axis. The experimental work consist of casting $\mathrm{RC}$ beam-column joints in controlled beam-column joints, design for torsion beamcolumn joints, and fully wrapped with aramid fiber beamcolumn joints each 3 specimen and curing this specimen for 7,14,28 days and testing this test specimen under "Loading Frame".
\end{abstract}

\section{INTRODUCTION}

Concrete is the development material which is utilized by every one of the people groups on the planet generally broadly.Seismic outline centers on the malleability of an edge as the fundamental structure to oppose the sidelong power. This condition is dictated by the basic individuals, particularly beams and columns. In this manner, the joint must be adequately pliable till beams and columns accomplish their heap limit. Amid the inelastic twisting of the beams and columns outside the flexible range, expansive distortion will be included bringing about unmistakably noticeable harm. These power impacts are called plastic pivots. The inelastic turn spreads at specific territories. At the point when the joint endures inelastic revolution, the pliability limit of all individuals are exchanged to the joint with the goal that the harm at the joint is will be generous and ought to be maintained a strategic distance from. The arrangement of a plastic pivot is normal, where allowed auxiliary harm happens. Hence, it is vital in seismic outline that the harm of a plastic pivots happens in the beam, instead of in the column.
The beam column joint is the pivotal zone in a strengthened solid minute opposing edge. It is subjected to expansive powers amid extreme ground shaking and its conduct affects the reaction of the structure. In RC Structures the quality of the structure lies both in support and solid clinging to shape an auxiliary part. The basic part can be a Beam, Column, or a Section. The Disappointment of a structure can be caused because of a few reasons, the primary reason can be Beam-Column joint disappointment. The beamcolumn joint must be outlined with additional care to stay away from the disappointment of structure.

\section{OBJECTIVE}

1. The objective of this experiment is to investigate the behavior of concrete wrapped with aramid fiber in the beam-column joint.

2. Mix proportion for M30 grade concrete is arrived by different section type of reinforcement induced through the concrete.

3. To obtain strength and durability characteristics of concrete with using Aramid fibre as a wrap.

4. To obtain the suitable mix design for aramid fibre as a wrap.

5. To obtain the avoiding crack on the beam-column joint with using aramid fibre.

6. To obtain the effective strength of concrete using aramid fibre as wrap.

\section{LITERATURE REVIEW}

1. Utkarsh R.Nishane1, Nitin U. Thakare2 et al (2017) Experimental studies on fiber reinforced concrete - For glass and steel reinforcement, strength of concrete increased with, increased in fibre dosage up to $0.5 \%$ as compared to glass fibre, aramid fibre gives $48 \%$ more compressive strength, whereas when comparing aramid and steel fibre, aramid gives $66 \%$ increased compressive strength. Aramid reinforced concrete produce massive compressive strength as here, the aramid reinforced concrete is introducing compressive strength as equal to M35 grade in design of M20 grade. 
2. Er. KhairnarNilesh K, Prof. Kandekar S.B, Dr.R.S.Talikoti ET al.The FRP material, for example, Aramid fiber having high quality extreme and exceedingly natural fiber got from polyamide is helpful for reinforcing beam-column joint. The point of this paper to look at the Torsional conduct of beam-column joint and the execution of Aramid fiber in restoration of harmed beam-column joint. Also, trial result and the Torsional limit of controlled beamcolumn joint, outline for torsion beam-column joint and completely wrapped with Aramid fiber beam-column joint acquired.

3. Mahmoud M. Eldeeb, Kamal GhamryMetwally, Adel YehiaAklet al. This paper focuses on investigating the efficiency of using Carbon Fiber Polymer (CFRP) sheets on the behavior of beam-column connections considering a cantilever beam with concentrated load at its free end. In this case, framing action between beam and column is the only path to dissipate the earthquake $(E Q)$ energy, which is a significant matter when such connection is not designed to withstand such energy.

4. A.G.Tsonos, I.A Tegos and G.GrPenelis et al. (1992)strategy to keep the beam-column components from flopping in untimely, touchy cleavage shear disappointment was executed out of the blue. Twenty examples were tried. The essential factors were the measure of slanted bars, the proportion of the column - Tbeam flexural limit, and the joint shear pressure. Test outcomes demonstrated that utilization of crossed slanted bars in the area is a standout amongst the best approaches to enhance the seismic protection of outside reinforced solid beam column joints.

5. M.Engindeniz, L.F, Kahn, and A.-H.Zureick et al. (2009) strategy to keep the beam-column components from flopping in untimely, touchy cleavage shear disappointment was executed out of the blue. Twenty examples were tried. The essential factors were the measure of slanted bars, the proportion of the column - Tbeam flexural limit, and the joint shear pressure. Test outcomes demonstrated that utilization of crossed slanted bars in the area is a standout amongst the best approaches to enhance the seismic protection of outside reinforced solid beam column joints.

\section{MATERIALS}

\section{Cement}

Cement have an important binding material of concrete. The Ordinary Portland Cement have used in this experiment. The Ordinary Portland Cement was classified into three grades, which is 33 grade, 43 grade and 53 grade these were depending upon the strength of the cement at 28 days. The cement confirming to IS - 12269 was used. The physical property of cement lies within range as per IS -4031 . All the property of cement is tested.

\section{$>$ Coarse Aggregate}

The coarse aggregate was the important constituents in the concrete. This are reduced the shrinkage of concrete and economy of effect. In this study coarse aggregate of size 12 $\mathrm{mm}$ and $20 \mathrm{~mm}$ are used. The coarse aggregate should be selected with appropriate size, shape, porosity, texture, absorption etc. The angular aggregate should be used instead of elongated and flakiness aggregate as the angular aggregate was durable and shows higher strength property.

As per the Indian Standard codes, the material should be tested. The sieve analysis test procedure as per IS 2386 (Part 1): 1963, the specific gravity and absorption test as per IS 2386 (Part Ш): 1963, the sampling materials should be done as per IS 2430: 1986.The coarse aggregate is tested for its properties such as specific gravity, fineness modulus, bulk density, water absorption.

\section{Fine Aggregate}

The possessions of fine aggregate should be tested and material within the specified limits area selected. Stream sand of size less than $4.75 \mathrm{~mm}$ size were used as fine aggregate. The Indian Standard codes for test concern are, the sieve analysis test undertaken as per IS 2386 (Part I): 1963, and the specific gravity and water absorption as per IS 2386 (Part III): 1963 , for test process material specimen should be done as per IS 2430:1986. Sand has tested for its properties like bulk density, specific gravity, and fineness modulus and water absorption. The fine aggregates were mostly used for filling material of concrete. Which isgive the body of the concrete.

\section{Water}

The water is natural resource, which is used by the concrete for providing the strength. Water is one of the important constituents of concrete as it aggressively participates in the chemical reaction along with cement. And it helps to form the strength providing cement gel, the quantity and quality of water is considered very judiciously. The water taken in this learning as per the necessities of specified in IS 456. In this learning clean natural water is used.

\section{Aramid Fiber}

Aramid fiber is man-made artificial high performance fiber. These molecules are characterized by comparatively rigid polymer chains. It was good resistance to the organic solvent. Aramid fiber was recycled in bullets resistance jacket. This fiber had good abrasive resistance and under repeated loading, they can scratch against each other by weakening the sheets. The aramid fiber is prepared from synthetic products and characterized by strength. It is five times stronger than steel on an equal weight source and heat resistance and great tensile strength. The thickness of aramid fibre $1.5 \mathrm{~mm}$, and size of aramid fibre is $4.0 \times 1.2 \mathrm{~m}^{2}$. The density of aramid fibre is $1.44 \mathrm{~g} / \mathrm{cm}^{3}$ and elongation is $2.8 \%$. 


\section{MIX DESIGN (M30 Grade)}

$\begin{array}{ccccccc}\text { Cement } & : & \text { Fine Aggregate } & : & \text { Course aggregate } & : & \text { Water } \\ 394 & : & 803 & : & 992 & : & 185 \\ 1 & : & 2.04 & : & 2.52 & : & 0.44\end{array}$

Abaqus is a software for finite section examination and computer helped engineering, originally unconfined in 1978. The abaqus software application used for both the displaying and study of mechanical workings and associations and imagining the finite section examination. The beam-column joints specimens are analyzed by this software and also three different types of reinforcement are analyzed by this software.

\section{TESTING SPECIMEN}

\section{Hardened Concrete Test}

Testing the Cube, Cylinder and Prism each specimens tested at 7 days, 14 days and 28 days

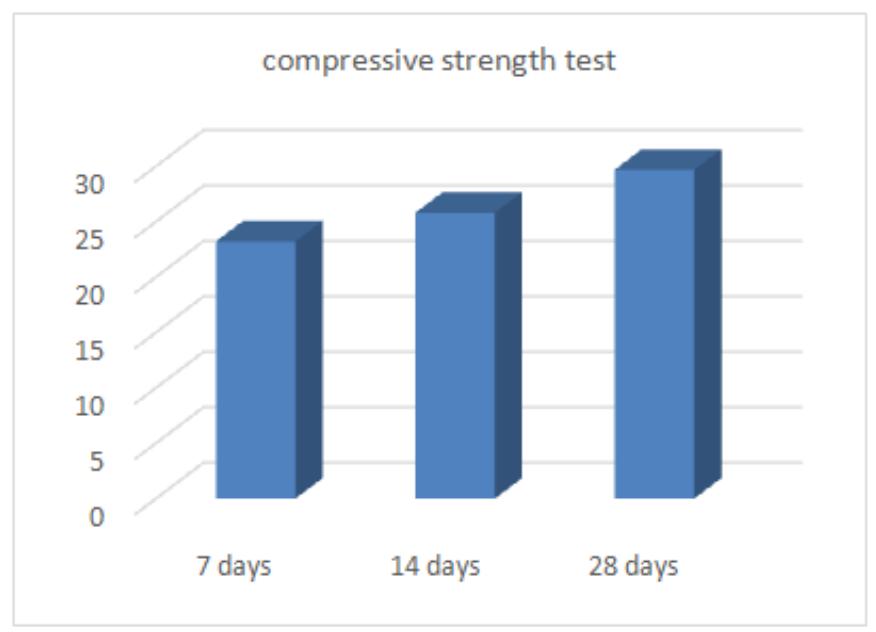

Fig.1 compressive strength

ISSN No:-2456-2165

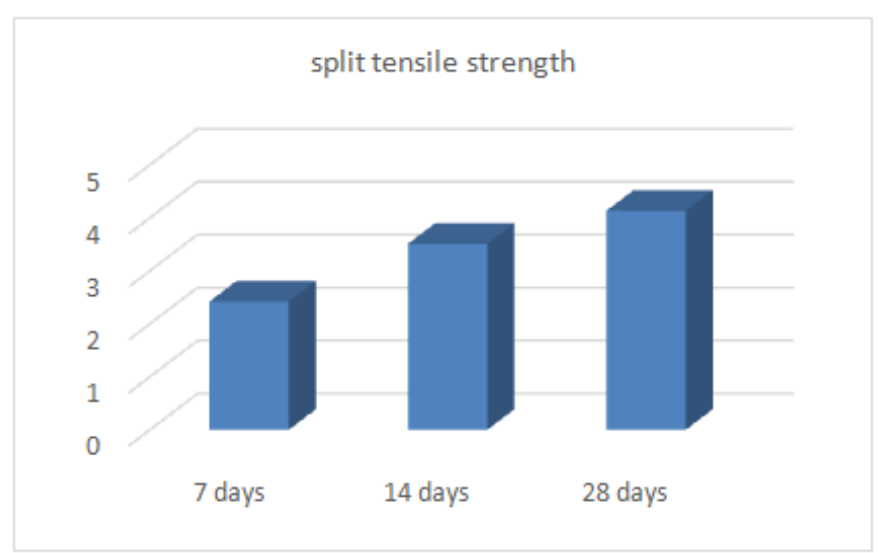

Fig.2 Split tensile strength

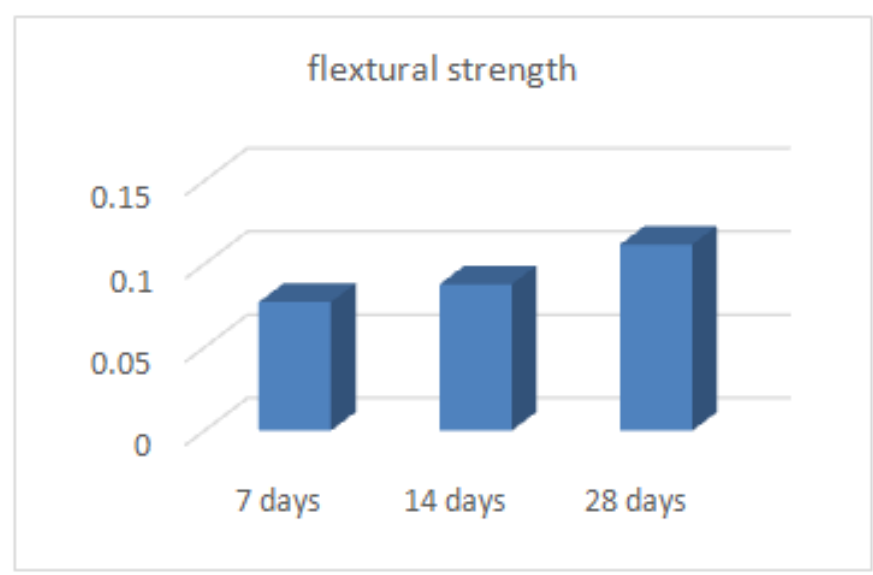

Fig.3:- Flexural strength for prism for cube for Cylinder

VIII.

\section{STRENGTH TEST ON BEAM COLUMN JOINTS}

The strength test was conducted for beam column joint specimen. This beam column joints are casting with three different type steel reinforcement that is a conventional mix of concrete. This three section depends to tested the BeamColumn Joints at different curing days.

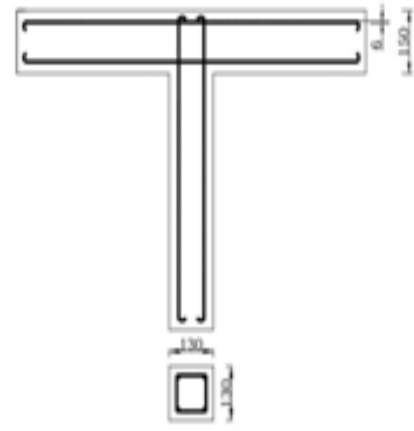

A SECTION TYPE REINFORCEMENT

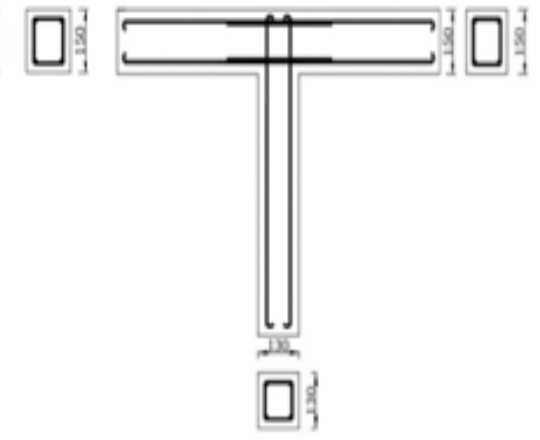

B SECTION TYPE REINFORCEMENT

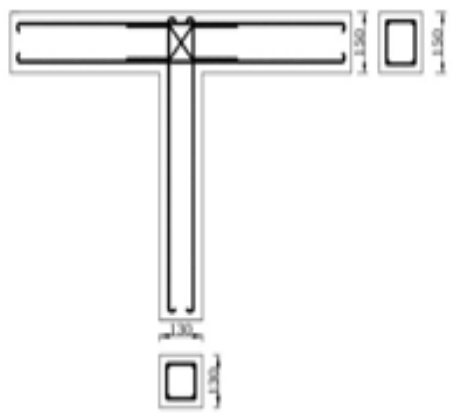

C SECTION TYPE REINFORCEMENT

Fig.4 :- A, B,C Section Type Reinforcement 


\section{OVERALL STRENGTH OF THE BEAM- COLUMN JOINT}

The following figure shows that the overall strength of the beam column joints for conventional concrete.

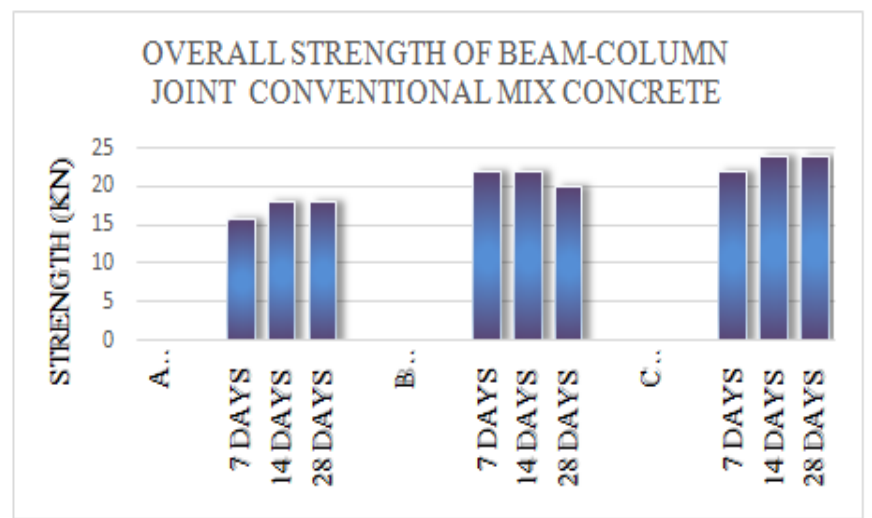

Fig. 5. Overall strength of conventional concrete

The following figure shows that the overall strength of the beam column joints for wrapped aramid fiber on surface of the concrete.

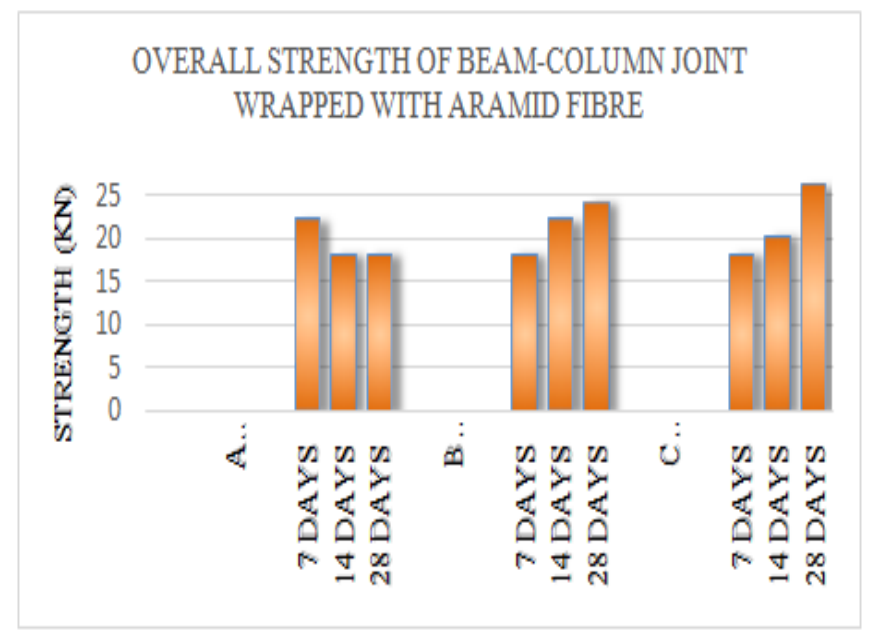

Fig.6 Overall strength for aramid fibre concrete

\section{ABAQUS ANALYSIS}

The following figures shows that the effect of loads to the beam-column joint of conventional concrete (A section type reinforcement), this figures are drawn by the abaqus software. This software use to analysis the Beam-Column Joint Behaviour that mean joint how to deflect the building that all are study in this software used. Beam-Column Joint test study the Deflection, Stress, Strain etc.,

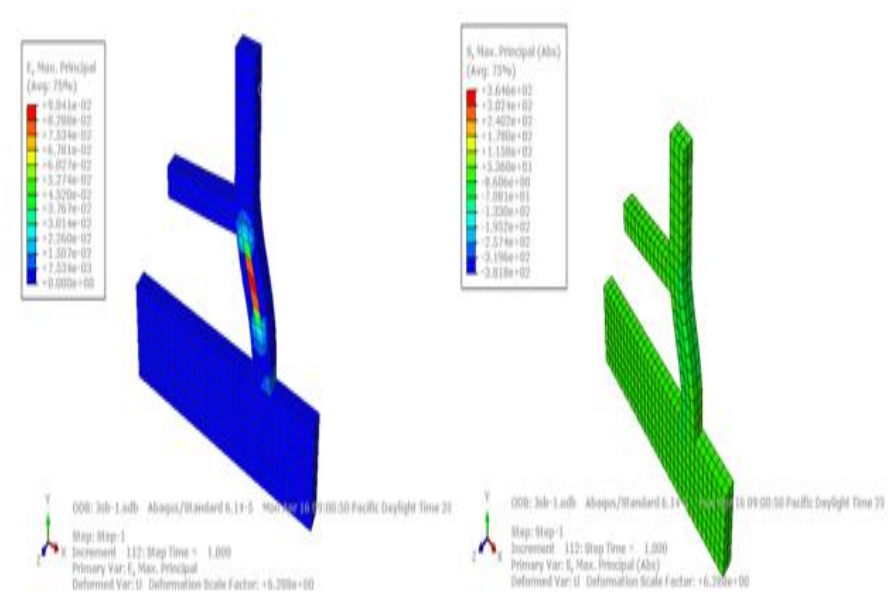

Fig.7 Example Fig for Maximum Stress and Strain

\section{CONCLUSION}

In this experimental investigation the strengthening of the beam-column joint and wrapped with aramid fibre.ere tested and compared with results of analyzed by ABAQUS software.

This results describes the ultimate strength of the beamcolumn joint at three different steel reinforcement details with appropriate curing period. In the A section type reinforcement gives conventional reinforced ultimate load is $16 \mathrm{KN}$ and wrapped aramid fibre ultimate load is $22 \mathrm{KN}$ at 7 days. This loads are compared in the ABAQUS analysis. This type reinforcement gives conventional reinforced ultimate load is $18 \mathrm{KN}$ and wrapped aramid fibre ultimate load is $18 \mathrm{KN}$ at 14 days. This loads are equal to each other and compared in the ABAQUS analysis. This type reinforcement gives conventional reinforced ultimate load is $18 \mathrm{KN}$ and wrapped aramid fibre ultimate load is $18 \mathrm{KN}$ at 28 days. This loads are also equal to each other and compared in the ABAQUS analysis. This ABAQUS analyzing value is $21 \mathrm{KN}$, this is higher compared with the each A section type reinforcement.

In the B section type reinforcement gives ultimate load is $22 \mathrm{KN}$ and wrapped aramid fibre ultimate load is $18 \mathrm{KN}$ at 7 days. This loads are compared in the ABAQUS analysis. This type reinforcement gives ultimate load is $22 \mathrm{KN}$ and wrapped aramid fibre ultimate load is $22 \mathrm{KN}$ at 14 days. This loads are equal to each other and compared in the ABAQUS analysis. This type reinforcement gives ultimate load is $20 \mathrm{KN}$ and wrapped aramid fibre ultimate load is $24 \mathrm{KN}$ at 28 days. This loads are also equal to each other and compared in the ABAQUS analysis. This ABAQUS analyzing value is $28 \mathrm{KN}$, this is higher compared with the each $\mathrm{B}$ section type reinforcement. 
In the $\mathrm{C}$ section type reinforcement gives ultimate load is $22 \mathrm{KN}$ and wrapped aramid fibre ultimate load is $18 \mathrm{KN}$ at 7 days. This loads are compared in the ABAQUS analysis. This type reinforcement gives ultimate load is $24 \mathrm{KN}$ and wrapped aramid fibre ultimate load is $20 \mathrm{KN}$ at 14 days. This loads are other and compared in the ABAQUS analysis. This type reinforcement gives ultimate load is $24 \mathrm{KN}$ and wrapped aramid fibre ultimate load is $26 \mathrm{KN}$ at 28 days. This loads are compared in the ABAQUS analysis. This ABAQUS analyzing value is $29 \mathrm{KN}$, this is higher compared with the each $\mathrm{C}$ section type reinforcement.

\section{REFERENCES}

[1]. AppaRao.G, M,Mahajan , M. Gangaram and Role Eligeshausen " Performance of non-seismically designed $\mathrm{RC}$ beam column joints strengthened by various scheme subjected to seismic loading", Journal of Structural engineering,V.35, No.1,Apr -May 2008, pp52-58.

[2]. AlyAS,Abdelaziz AF, Zaher AH, Awad BB. "Strengthening of R.C Beam Column Joint Under Seismic Loads Using of Recent Material" 2015;4(11):124-42.

[3]. Bindhu KR, Sreekumar KJ. "Seismic Resistance of Exterior Beam Column Joint with Diagonal Collar Stirrups" 2011;2(1):160-75.

[4]. C.R.Murty,Durgesh C. RaiBajpai, and SudhirK.Jain, "anchorage Details and joint Design in Seismic Rc Frames", the Indian concrete Journal, April 2001, pp. $274 / 280$.

[5]. Chalioris CE, Karayannis CG, Favvata MI. "Cyclic testing of reinforced concrete beam-column joints with crossed inclined bars" WIT Transactions on Modelling and Simulation, 2007;46:623-32.

[6]. "Experimental investigation of rehabilitation of reinforced cement concrete exterior beam-column joints by usinggfrp materials", 2015;7(5):92-100.

[7]. Francis TKA, Kun H, Hoat JP, Au FTK, Huang K, Pam HJ. "Diagonally-reinforced beam-column joints reinforced under cyclic loading" Structural and Building 158 Issue SBI, 2005;158(1):21-40.

[8]. Gnanapragasam AA, Chitra G, Ravi SR. "Study on strengthening of RC beam column joint using hybrid FRP composites" Circuits and Systems, 2016;7(August):2846-56.

[9]. Hooda N, Narwal J, Singh B, Verma V, Singh P. An. "Experimental Investigation on Structural Behaviour of Beam Column Joint” 2013;(3):84-8.

[10]. Kitayama.K, Otani.S and Aoyama.H, "Design of Beam column joints for seismic resistance" ACI SP -123, American Concrete Institute , Michigan,1991, pp 56-65.

[11]. Lakshmi.G.A, AnjanDutta and S.K.deb "Numerical studies of Strengthening of beam-column joint under cyclic excitation using FRP composites" joural of structural Engineering, Vol 35,No1, Apr-May 2008, pp. 59-65.
[12]. Leon R.T "Shear strength and Hysteric Behavior of interior Beam column joints" The ACI Structural journal, V.87,1990,pp 3-11.

[13]. Murty. C.R,Durgesh C. RaiBajpai, and SudhirK.Jain, "anchorage Details and joint Design in Seismic Rc Frames", the Indian concrete Journal, April 2001, pp. $274 / 280$.

[14]. Preedachaimahawan\&Amornpimanams "seismic retrofit of substandard beam column joint by planer joint expansion", material and structures, DOI 10, June May 2008.

[15]. Park, R., Paulay, T. "Reinforced Concrete Structures", New York, John Wiley\& Sons, 1975.

[16]. Pantazopoulous.s and Banacci.J, "Considerations of questions about Beam- Column joints", The ACI structural Journal V.89, 1992, pp 27-36.

[17]. Prota .A, A.Nanni, G.Manfredi, E.Cosenzea "Seismic upgrade of Beam-Columnjoint with FRP Reinforcement", Industrial Italian a del cement, Nov 2000.

[18]. Paul S.Baglin and Richard H.Scott "Finte element modeling of reinforced concrete Beam-Column joint", ACI Structural journal, V.97, No.6, Nov-Dec2000. 